\title{
Improving Community-level Governance: Adaptive Learning and Action in Community Forest User Groups in Nepal
}

\author{
RB Shrestha*, Sohan L Shrestha*, Sudil G Acharya* and Shrikanta Adhikari* \\ * Livelihoods \& Forestry Programme (LFP), Nepal \\ Corresponding author: rbshrestha@Ifpterai.org
}

\begin{abstract}
It is widely believed that Participatory Monitoring and Evaluation (PM\&E) can help community organisations improve their internal learning and governance. However, the processes of programme monitoring and evaluation as practised by many organisations lack the elements of community participation and ownership and the appreciation of its contribution to community learning. Wider lessons on participatory development demonstrate that only locallyinitiated and community-led monitoring can improve communities' performance and change their institutional practices. Drawing on the recent experience of Livelihoods and Forestry Programme (LFP), this paper makes the case for community-generated planning, selfmonitoring and evaluation for adaptive learning and good governance in Community Forest User Groups (CFUGs) in Nepal. These processes, conceptualised as Adaptive Learning and Action (ALA), have enabled CFUGs to identify their vision, formulate activities to achieve the vision, and regularly monitor the progress against the identified indicators. The process has also enhanced transparency, participation and accountability in CFUG governance.
\end{abstract}

Key words: governance, community forest, planning, stakeholders, adaptive learning and action, participatory monitoring and evaluation

\section{INTRODUCTION}

Community organisations are increasingly being recognised as foundations for grassroots development, democratisation and natural resource management (Agrawal and Gibson 1999). In recent years, agendas of change, such as decentralisation and good governance, have placed local communities at the centre of the change process. In this connection, Community Forest User Groups (CFUGs) have become a key agent of change at the grassroots. This has been possible as the CFUGs spread throughout Nepal and encompass over ten million people. The CFUGs are also legally recognised and serve as self-perpetuating community organiations. They have community-owned forest resources to fulfil the demand of forest products and to sustain their institutional functioning. However, these are relatively new community institutions and their planning, implementation and monitoring practices are yet to mature.

This paper discusses Adaptive Learning and Action (ALA) process that aims to improve governance in the CFUGs. Based on the experience of over ten years of the Livelihoods and Forestry Programme (LFP) funded by the UK's Department for International Development (DFID) in Nepal, we present how adaptive learning process takes place, improves planning and self-monitoring, and ultimately contributes to improved governance of CFUGs. The paper finally concludes that the adaptive learningbased governance processes within CFUGs have contributed significantly to improving the livelihood outcomes, equity and inclusion, and forest sustainability.

\section{CONTEXT OF AND SPACE FOR ADAPTIVE LEARNING AND ACTION}

Good communication linkages between people, groups and institutions in terms of sharing of power and responsibilities have been recognised as an element of good governance (Ojha et al. 2003, Ojha 2008). Transparency of organisational procedures, democratic decisionmaking, and accountability of members are important for the good governance of 
community organisations. To promote a learning-oriented culture and good governance in CFUGs in Nepal, District Forest Offices (DFOs) and forestry sector development agencies have taken up important initiatives. Despite the proliferation of participatory tools during the past two decades, community institutions in Nepal, as well as globally, suffer weak internal governance. Most of Nepal's 16,000 CFUGs have not yet been able to effectively manage their forest resources, with far less impact on livelihoods than would have ideally been possible (Hamilton et al. 2000, Ojha et al. 2003). One of the reasons behind this is the limited use of participatory approach in practice and continuation of top-down approach in more subtle ways (Cook and Kothari 2001, Ojha 2008).

Monitoring and Evaluation (M\&E) has long been applied by governments and development funding agencies to assess the actual change against the stated objectives and to determine the success of development assistance (Guijt 1999). Conventionally, M\&E involves external experts measuring performance against preset project indicators, using standardised procedures and tools (IDS 1998). In such a conventional approach, M\&E is fully controlled by the experts, where local people and stakeholders simply provide information as solicited by the experts, with little opportunity to reflect upon whether and how the information will be of any use to them. The main objective of such M\&E is to report to donors or governments in order to justify the use of their resources and judge achievements against the already set indicators, rather than helping the community groups to learn and improve their practices. As a result, neither the community nor the implementing agency gets sufficient opportunity for learning and improving from such M\&E.

With the commencement of participatory approach in the 1980's, there is increased recognition of the participation of the beneficiary groups in the practice of M\&E. Consequently, a variety of development organisations and community institutions are using M\&E for internal learning and continual improvement in their work (Guijt 1999). However, a more recent interest in Participatory Monitoring and Evaluation (PM\&E) has encouraged multi-stakeholder participation in programme planning and monitoring. A key task which the PM\&E entails is the assessment of changes through processes that involve many people or groups, each of whom is affecting, or is affected by, the impact being assessed (ibid). It further empowers stakeholders and enhances their public accountability. Different development organisations are now applying it under different names, e.g. Participatory Evaluation (PE), Community Monitoring/Citizen Monitoring (CM), Participatory Planning, Monitoring and Evaluation (PPM\&E), Selfmonitoring and Evaluation (SM\&E), and so on. Whatever the nomenclature, the ultimate objective of PM\&E is to enhance the effectiveness of programme by promoting internal learning and improvement. However, members of beneficiary groups from rural communities generally have little influence over such processes due to the domination of external experts and stakeholders. Communitylevel institutions enjoy and learn from the processes only when monitoring takes place against change indicators that are developed by them. Use of change indicators defined by community groups as well as effective networking and participatory planning can improve micro-level governance of community organisations.

In recent years, there is increased appreciation of community-centred planning and monitoring systems that builds on participatory and multistakeholder innovations, as well as increased recognition of the weaknesses of external influence over community-level governance in the traditional planning and monitoring processes. We conceptualise this communitycentred planning, monitoring and evaluation approach as ALA. This approach shares some commonalities with multiple strands of innovative development thinking such as adaptive management (Lee 1993), adaptive collaborative approach (McDougall et al. 2008), 
learning organisation (Senge et al. 1990) and self-monitoring (Malla et al. 2002). In a nutshell, ALA recognises that a) the communities are at the centre of learning process; b) the learning process starts with visioning and then passes through planning, self-monitoring and selfevaluation; and c) in all stages, there are dynamic and interactive communication links with concerned stakeholders who provide regulatory, institutional, developmental and technical services to the communities. In this article, we demonstrate that ALA enables CFUGs to change the process, if necessary, in order to deal with complexities and the changed context; improves governance; and enhances sustainable and equitable livelihood benefits. In other words, it enhances the community's competence to solve their problems using stepby-step procedure with the use and mobilisation of their own skills and resources. In addition, ALA influences governance of other stakeholders who have links with the community. This finding is drawn from a number of CFUGs in the LFP areas who were supported to apply the ALA.

\section{GENESIS OF ADAPTIVE LEARNING AND ACTION INITIATIVES}

Different community forestry programmes and projects have tried to enhance effective and learning-oriented CFUG management. In the early 1990's, the DFID-supported Nepal-UK Community Forestry Project (NUKCFP) piloted a couple of processes and monitoring systems to enhance the learning culture and good governance in CFUGs. Together with the DFO staff and CFUGs, learning-focused monitoring systems were promoted, and various tools and processes such as CFUG health check, usergenerated pictorial decision-making in SM\&E, SM\&E in information management, and "CFUG planning and SM\&E" were developed.

The "CFUG health check" used a checklist with four main sections: a) forest resource management, b) social and institutional development, c) awareness and flow of information, and d) skill development initiatives. The DFO staff used to collect information based on the checklist and select the best CFUG in the district every year. However, the process was completely owned by the DFO staff with no opportunity for CFUGs to learn and improve. Later in 1996, the NUKCFP piloted "usergenerated pictorial decision-making" tool in $S M \& E$ with specific focus on enabling the participation of illiterate CFUG members in the process. This process continues only in a few CFUGs. Some of the CFUGs practised participatory information management following SM\&E with the support from the NUKCFP.

Later, in Sankhuwasabha district, the members of Dhungedhara Thulopakha CFUG and the NUKCFP jointly developed "CFUG planning and SM\&E" tool that was largely led and owned by CFUGs. The tool guides CFUGs through a reflective and deliberative process to envision their ideal status considering holistic development needs, to make plans to achieve their goal, and to monitor their progress at regular intervals. After the CFUG gained some experience with positive results, it was invited to share the advantages of SM\&E with other CFUGs and forestry staff during the range post, district and regional level interactions and sharing meetings. As the interest grew, the project team gradually scaled up its use in other CFUGs within and outside the district and developed facilitation skills of the DFO and NGO staff at the district level. To disseminate the process, NUKCFP produced a process video and trained the NUCKFP and DFO staff to facilitate CFUG to replicate the process. The process has been

adapted and used by many CFUGs, and several implementing partners such as DFOs shown interests in scaling out the innovations widely in the area. As more experience was gained, the LFP staff and partners reflected upon the practice of SM\&E processes, and in order to capture the complexity of the process, the author proposes to reconceptualise the innovation as ALA, which allows capturing broader aspects of learning and action, beyond 
monitoring and evaluation which was the focus initially. The ALA was launched not only in Sankhuwasabha but also in other LFP districts, viz. Bhojpur, Dang, Dhankuta, Nawalparasi, Parbat, Rukum, Salyan and Terhathum.

\section{ADAPTIVE LEARNING AND ACTION: STEPS, TOOLS AND TECHNIQUES}

The ALA methodology allows CFUGs to visualise an ideal situation and define its indicators in terms of organisational development and forest and livelihood outcomes, and to develop a plan of action to achieve its vision. It is also sensitive to the political inequality among CFUG members, and enables CFUG leaders to consider aspects of equity and inclusion in the process. The CFUGs implement their plan by mobilising internal resources and by accessing external resources and services. They then assess the changes achieved in terms of processes and outcomes to achieve the vision. Beyond a linear model of planning-implementing-monitoringevaluation, ALA emphasise complex, iterative and dynamic interaction among the members over the vision, practices and issues. The ALA utilises a set of carefully designed pictorial tools to present and discuss indicators that creates a pleasant and more equal learning environment for both literate and illiterate members. The whole process of ALA can be presented in four stages (Table 1), as discussed below.

Table 1: Adaptive Learning and Action Stages, Process and Outcomes

\begin{tabular}{|c|c|c|}
\hline Stage & Process & Outcome \\
\hline Preparatory & $\begin{array}{l}\text { - Meeting with CFUG office- } \\
\text { bearers/committee members }\end{array}$ & $\begin{array}{l}\text { - Clarity on what ALA is, including } \\
\text { processes and steps } \\
\text { - Increased ownership of users over the } \\
\text { process }\end{array}$ \\
\hline $\begin{array}{l}\text { Visioning and } \\
\text { planning }\end{array}$ & $\begin{array}{l}\text { - Organising hamlet-level meetings } \\
\text { - Organising joint meeting of hamlet } \\
\text { representatives }\end{array}$ & $\begin{array}{l}\text { - Development of indicators for the vision } \\
\text { indicators } \\
\text { - Areas of intervention prioritised and plan } \\
\text { prepared }\end{array}$ \\
\hline $\begin{array}{l}\text { Putting the } \\
\text { plan into } \\
\text { action }\end{array}$ & $\begin{array}{l}\text { - Delegation of responsibilities to } \\
\text { members } \\
\text { - Implementation of plan }\end{array}$ & $\begin{array}{l}\text { - Action taken as per the plan in order to } \\
\text { ensure that targets for each indicator are } \\
\text { achieved. }\end{array}$ \\
\hline $\begin{array}{l}\text { Monitoring, } \\
\text { review and } \\
\text { revision }\end{array}$ & $\begin{array}{l}\text { - Monitoring of progress towards } \\
\text { vision } \\
\text { - Review and improve indicators }\end{array}$ & $\begin{array}{l}\text { - Progress towards the vision tracked } \\
\text { - Vision indicators improved }\end{array}$ \\
\hline
\end{tabular}

\section{Preparatory Stage}

To ensure that the process is fully owned by the CFUG, sufficient understanding of the purpose should be developed among its key members. Facilitators discuss the process and advantages of ALA with Executive Committee (EC) members of the CFUG at their regular meetings. Once the key members realise the value of the process, they then carry forward the process themselves with the participation of other members too. It is very important that CFUG members lead the process themselves so that other members accept this as their own and commit to its continuity without external facilitators. Facilitators should prepare the plan for creating the environment conducive to learning for everyone, particularly the poor, dalits, women, and marginalised. In this sense, facilitators have crucial role at the preparatory stage of the process, and the quality of the subsequent process and outcomes depend on the actual facilitation techniques and strategies used by the facilitators. The ALA approach has developed specific facilitation strategies that enhance dialogue, reflections and open interactions rather than prescriptions of standard ALA methods and tools. 
The preparatory stage sets out specific course of actions to be taken and a clear division of responsibility. Based on the size of the CFUG, the community members fix the number of meetings to be held, set dates and venues, and take steps to ensure participation of every household. They divide the responsibility for communication about the meeting. The facilitation team, which includes EC members too, makes necessary preparation to assist the CFUG for the whole process of ALA.

\section{Visioning and Planning}

The facilitators may want to introduce the visioning and planning process through a skit, asking a volunteer from the group to look in a mirror at the hamlet-level meeting. The facilitators try to confuse the volunteer by putting dry colour on her/his face and asking her/him to look at the mirror. Based on the views of the volunteer expressed before and after looking in the mirror, the facilitator explains what self-monitoring is and why it is necessary. Similarly, the facilitators then may want to perform a role play, building on a conversation of rural farmers about the day-today observation of their paddy field and agricultural activities. Based on the discussion and feedback on the role play, the facilitators summarise and explain to the CFUG members that monitoring is not a new practice and also not a one-time event, but that it should be conducted periodically and pro-actively in order to effectively learn from practice.

Once the members are ready to do ALA in their CFUG, an exercise is carried out in order to envision the characteristics of an ideal CFUG in the next five to ten years. The facilitators help them to describe the characteristics of their ideal CFUG in key aspects, such as governance, social inclusion, forest management, pro-poor development and community development, and networking. Then these become indicators, which are noted down and used to measure the scale of progress in due course of time. The CFUG members are asked to draw pictures to represent each indicator. As some of the members might never have used a pen, the facilitators encourage them to start using one. Once they start drawing, the environment becomes more pleasant to all. When this task has been completed, all members share their pictures and take each other's feedback.

The facilitators then help the group to assess the status of each indicator by comparing it with different phases of the moon. Generally, four stages of the moon, viz. no moon, early moon, more than half moon and full moon are presented, and the members are encouraged to discuss and put each picture below an appropriate stage of the moon to represent the status. Then, the participants prioritise the most important indicators for immediate action. Moreover, the CFUG members also map out its internal resources and potentials of different stakeholders to support its plan.

After the hamlet-level ALA exercise, a small team comprising facilitators and CFUG EC members compiles the data against the indicators and assessments. They are presented at a hamlet representatives' meeting at the CFUG level, where indicators are refined and priority areas are confirmed. The group then prepares long and short-term plans on how it is going to work towards achieving the vision, considering the internal and external resources it has access to. Once the plan is finalised, the CFUG formalises it through its regular meeting and/or assembly in accordance with its constitution.

\section{Putting the Plan into Action}

After the formal approval of the action plan of rolling out from the ALA process, the CFUG implements it. Responsibilities can be delegated to the EC members and/or hamlet-level subcommittees to implement the plan effectively. Then the responsible member or subcommittee coordinates with the different stakeholders and mobilises support for effective implementation of the action plan.

\section{Monitoring, Review and Revision}

The CFUG periodically monitors the progress towards the achievement of the vision through ALA. It shares success story with all members 
and identifies the areas for improvement. Progress towards its vision may encourage the CFUG to continue their activities. Similarly, the identification of areas for improvement prepares the CFUG to initiate further actions. The CFUG then updates the Constitution and Operational Plan (OP) on the basis of ALA outcomes, which make implementation of activities legitimate and easy. The outcomes of ALA may further suggest revising CFUG's vision and indicators so as to contribute achieving CFUG's ideal vision and indicators.

\section{TRANSFORMING GOVERNANCE THROUGH ADAPTIVE LEARNING AND ACTION: A CASE OF DHUNGEDHARA THULOPAKHA CFUG}

Dhungedhara Thulopakha CFUG in Khandbari Municipality in Sankhuwasabha district is one of the biggest CFUGs in Nepal's hill districts. A total of 205 households were organised into this group to manage 218 hectares of well-stocked sal (Shorea robusta) forest. The CFUG, being close to district headquarters, faced tremendous pressure for supply of forest products, especially fuelwood and small timber. The community is heterogeneous and comprises people who migrated there from different parts of the district. When NUKCFP team visited in 1997 it seemed that the group has limited collective ownership over the forest.

During a regular follow-up visit by NUKCFP staff in 1997, the CFUG EC shared the problems faced by it while managing the group. The EC was of the view that unity and commitment of CFUG members towards forest management activities were lacking. The EC members told that the group was facing several problems, such as unauthorised extraction of forest products, conflicts between CFUG EC and general members, and passive involvement of members. In this context, the CFUG EC members and NUKCFP staff jointly designed a SM\&E (now conceptualised as ALA) process.
Based on the number of households and their locations, the CFUG members were divided into ten hamlets. The date and venue for hamlet meetings were fixed and communicated to all members by the EC members. The CFUG officebearers and range post staff played the role of facilitators along with the NUKCFP team to implement the process. At the hamlet meetings, the facilitators guided the CFUG members in finding out how their CFUG looked from the perspectives of governance and group management, pro-poor focused development, forest management, and coordination and networking. The facilitators helped them list their views, but without any interference. This allowed the CFUG members to develop their indicators free from the domination of external facilitators.

In each hamlet, the users drew up a list of indicators of an ideal situation in which they wanted their CFUG would be on. Then, they drew pictures to illustrate each indicator. Each member shared his or her picture to other members and received feedback. They assessed the situation using indicators against four stages of the moon ${ }^{1}$, which symbolised the various stages of the indicators (Table 2). The process of drawing pictures and carrying out assessment against the stages of the moon created a joyful and reflective learning environment for the users, and allowed them to envision the desired future as well as potential stages to pass through. Collective assessment of, and reflection on, the outcomes of the assessment helped them realise the importance of their intervention to achieve the desired situation. After completing hamlet-level assessments, they compiled the scores of indicators for the ten hamlet and developed common indicators, reflecting the existing status of the CFUG. They also analysed their available resources and mapped out possible stakeholders that could support their plans to achieve their desired status. Based on their assessment, they prioritised areas for intervention and made necessary plans. 
Table 2: Assessment of Dhungedhara CFUG in 1997 and 2007

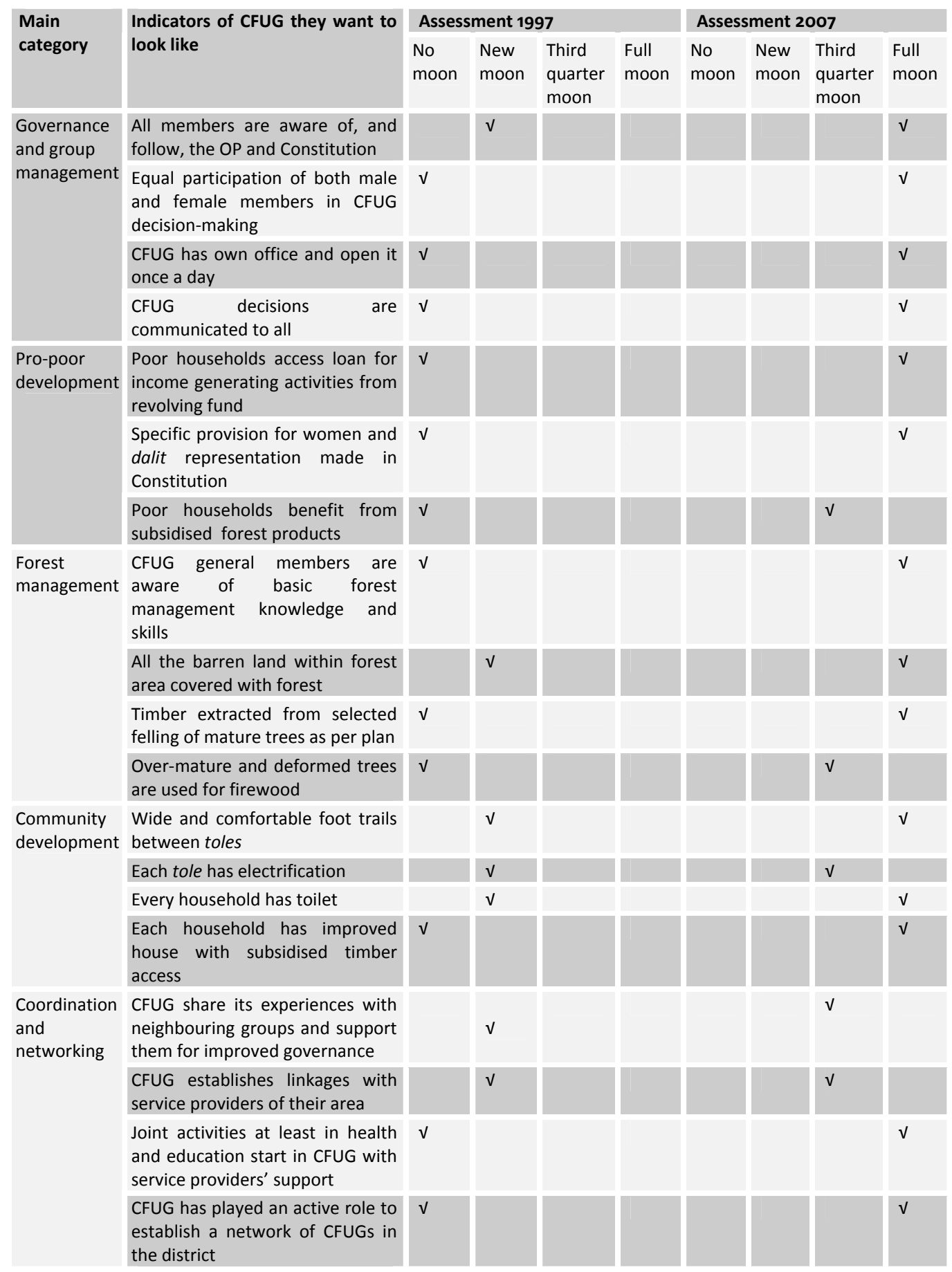

Source: Dhungedhara Thulopakha CFUG 
After introducing the ALA process in the CFUG, it made an annual plan and implemented it with the active participation of the members. The CFUG formed hamlet-level sub-committees, shared the CFUG Constitution and OP at hamlet meetings, constructed foot-trails for linking different settlements, and provided 6 cubic feet of timber to each of those houses that built toilets. Similarly, the CFUG established a propoor revolving fund, and provided loans to the needy poor households. The CFUG ran nonformal literacy classes for their illiterate members with the support of the District Education Office. They also conducted an outreach health education campaign with the District Public Health Office and health clinics in each settlement. These activities helped make the users aware of the health issues. Every year, they assessed their progress towards the full moon and plan for the next year. The conscious planning, action and reflection process regularly guided the CFUG towards achieving its ten-year vision.

As can be seen in the above table, the CFUG made considerable progress against each indicator. It reviewed indicators annually and improved them as per need. The CFUG had almost no moon or new moon stage in most of the indicators in 1997, and achieved its targets in 2007 as a result of its continuous effort for the ten years. Strong commitment of the EC and hamlet sub-committees, apart from regular follow-ups and actions, enabled CFUG to achieve its desired vision. Further, the CFUG was able to develop leadership at hamlet level, and is continuing the process with changed leadership. After ten years, every household has a toilet; each hamlet has electrification; and more than NRs 200,000 is mobilised for propoor income-generating activity. Poor and dalit women are sustaining their livelihoods from small businesses that they started with the support of the CFUG revolving fund. Now the users have become more supportive of the EC in its forest management activities, which has led to greater forest productivity and regeneration.

\section{CHANGES OBSERVED IN THE COMMUNITIES DUE TO ADAPTIVE LEARNING AND ACTION PROCESS}

The ALA process in most of the LFP districts is led and owned by the CFUGs for improving their governance. It is being replicated in more than 550 CFUGs in nine districts. The LFP has been supporting capacity development of facilitators, particularly DFO staffs and NGO partner and CFUG networks. The CFUGs and facilitators are encouraged to share the methods and advantages of the ALA process with other CFUGs at various forums and network meetings. The process has strengthened development initiatives, governance and social inclusion in CFUGs. It has guided CFUGs towards their visions, which has become the basis for their planning. A member of a CFUG in Mid-western Nepal said that they used to prepare plan only at the time of implementation. Now, following the application of ALA approach, they had learnt the importance of advance planning with clear guidelines. The process encourages members to seek transparency from their service providers as well. Moreover, the process helps members to realise the value of commitment and participation for the development of the groups. Identification of different stakeholders helps in working actively to get support from each of them, thus promoting useful linkages between service providers and CFUGs. The process guides CFUGs through institutionalising adaptive learning process to transform governance and to manage forest resources sustainably. The following sections briefly present the specific changes in four areas of governance, viz. a) common vision of the CFUG, b) active participation of forest users in institutional matters and forest management, c) accountability of the members on community welfare, and d) transparency of decision-making processes and resource utilisation. 


\section{Common Vision: A Way of Better Targeting}

A common vision with identified indicators is important for steering the organisation towards their aspirations for the defined timeframe ( 5 or 10 years). The ALA process supports the building of common vision and plan with active participation of all members. The process of using pictorial indicators and reflections of change in different stages of the moon makes even the illiterate members clear on what they want to achieve. Regular assessment of progress enhances the internal learning culture as well. Almost all CFUG members now realise the need of continuous monitoring. The expected ideal condition encourages them to work proactively for improvement. The common understanding of group vision enhances uniform and consistent dealing among CFUG members. This has promoted the CFUGs' trust among the service providers and local government institutions. The CFUGs' proactive behaviour, common understanding and learning-oriented working approach help them receive assistance from service providers.

\section{Active Participation: Enhancing Ownership of Group Activities}

Generally, people actively participate in those activities that they themselves decide to carry out. The development of common vision and plan with mass participation enhances the ownership of group activities. Use of pictorial vision and indicators further strengthen active participation and ownership of [even illiterate] members. The ALA process changed the culture of seeing EC as a controlling body and general users as mere recipients of development services to that of being complementary to each other in sharing responsibility and ownership. A member of Paluthan CFUG in Mid-western Nepal claimed that the participation of members in meetings, discussions, forest management and community development activities has increased after the introduction of the ALA process in the CFUG. Similarly, a former chairperson of Dhungedhara Thulopakha CFUG in Sankhuwasabha observed increased participation and contribution of women members in decision-making and forest management following the introduction of ALA in their CFUG. Formation of hamlet-level subcommittees and delegation of CFUG EC's authority to them have promoted regular discussions and participation of users. The practice of conducting hamlet-level meetings has helped development of alternative leadership within the group.

\section{Increased Accountability: Facilitating the Implementation of Group Activities}

While the CFUGs previously perceived that the monitoring is the sole responsibility of the DFO, the ALA process prompted them take it as their own responsibility. The ALA process promotes the practice of delegation of responsibilities and authority amongst the users. It makes all users more accountable for their group's activities. With the ALA, the CFUGs are taking initiative for the holistic development of their communities. Besides forest management and distribution of forest products, they are carrying out activities for social transformation, infrastructure development and education as identified by the group members. For example, Dhungedhara Thulopakha CFUG prohibited open sale of alcohol in the community.

The EC gains confidence of the CFUG members through more accountable and responsible behaviour. This, in turn, increases the contribution and support of the users in plan implementation. Continuous and unified efforts and improvements in the CFUG's activities help them to gain respect and recognition from other groups and stakeholders. The process further contributes to effective planning and mobilisation of internal resources and external resources and services.

\section{Transparency: Promoting Trust}

The ALA process establishes the culture of regular interactions at hamlet-level between CFUGs and EC members, and it enhances transparency in the planning, implementation and monitoring of the CFUG functioning. 
Hamlet-level meetings, regular assessments and delegation of authority to hamlet committees enhance transparency in CFUG activities. Transparency reduces conflict between the general users and the EC members and promotes trust between each other. The ALA process also promotes the joint planning that assigns the role amongst the members. Similarly, when forest users regularly assess progress against indicator, all users get updated on the actions and achievements of the group. This automatically contributes to learning and improvement in the functioning of the group. These processes and activities directly promote trust between the general users and EC members.

\section{ISSUES AND DISCUSSION}

The ALA process has been found as a practical process for defining the indicators of expected changes in CFUGs and for planning and implementing activities on their own leadership. However, its effectiveness depends on the commitment of and acceptance by the community, effectiveness of facilitation, and the availability of resources and time to implement the plan.

Effective communication of the process and its benefits among CFUG office-bearers and the social elites in the community is important for introducing the process into a group. If the process is not understood and accepted by CFUG office-bearers, it will be almost impossible to institutionalise it in the CFUG. Generally, CFUGs are convinced to adopt the process when they observe the effectiveness of its application in their neighbouring CFUGs. However, external facilitators can accelerate the scaling up of the process through frequent sharing and communication.

The scaling up of the process varies, depending upon its internalisation by facilitators and their commitment towards it. For example, scaling up of the process in the LFP project districts greatly varies despite its clear mandate of improving CFUG governance. It is partly due to the varied commitment and understanding of the programme staff at the central, regional and district levels. The staff that have either practised or observed the ALA process have internalised it as a practical tool and extended this process in CFUGs. However, without sufficient knowledge and skills, the process might be mechanical and may create confusion among the users.

The ALA process initiates new roles for CFUG EC and general members, and ushers a culture of shared responsibility. This enhances the commitment and responsiveness amongst members and it also challenges some of the existing practices. This creates a form of transition in CFUGs towards the new shift from top-down approach to participatory learning, and may take considerable time to adjust and establish the process as an institutional mechanism.

However, the effectiveness of the process varies, depending upon the availability of resources. Both internal and external resources are important for completing the process with intended outcomes. If CFUGs lack internal resources and cannot access external resources from service providers, they may get frustrated. While the application of the process can be facilitated by CFUG members themselves, the users in many cases depend upon external resources and facilitators. For instance, Dhungedhara Thulopakha CFUG is seeking assistance from the LFP even after more than ten years of having adopted the process.

\section{CONCLUSION AND IMPLICATIONS}

The paper concludes that CFUGs can improve their internal governance by following the ALA process in their group. Visioning, planning, action and self-monitoring are the key elements of the ALA process that increase the commitment, collective capacity and learning of CFUG members for sustainable resource management and livelihoods. Analysis of ALA experience in the LFP areas shows that this process helps CFUGs to envision their destination and to develop a plan to guide their actions, with an in-build mechanism for learning 
and improvement. It encourages CFUGs to enhance their effectiveness, accountability and responsiveness. It further strengthens CFUGs' understanding, skills and practices in relation to participatory and learning-oriented group governance in order to manage resources for sustainable livelihoods. The process also promotes CFUGs to proactively seek and mobilise internal and external resources.

Although the ALA approach is supported by relatively simple and easy toolkits, it has not been sufficiently scaled up across CFUGs in Nepal. If not properly facilitated, the ALA runs the risk of becoming a mechanical tool of facilitators and CFUG leaders, rather than serving as a learning-based process. Because of its process-intensive nature, development programmes are not always enthusiastic about it, despite positive outcomes at the CFUG level. It can be argued that the process needs to be scaled up to promote learning-oriented community governance across Nepal. The ALA process induced at micro-level governance has also the potential to influence meso and macrolevel governance, and the ALA as applied CFUGs has several things to offer that meso and macro-level agencies can learn from.

\section{REFERENCES}

Agrawal, A. \& Gibson, C. 1999. Enchantment and Disenchantment: The Role of Community in Natural Resource Conservation. World Development, 27: 629-649.

Cook, B. \& Kothari, U. 2001. The Case for Participation as Tyranny. In: B. Cook and U. Kothari (Eds.), Participation: The New Tyranny. Second (2002) edition. London and New York: Zed.

Guijt, I. 1999. Participatory Monitoring and Evaluation for Natural Resource Management and Research. Socio-economic Methodologies for Natural Resources Research. Chatham, UK: Natural Resources Institute.

Hamilton, C., Rai, R., Shrestha, R.B., Maharjan, M., Rasaily, L. \& Hood, S. 2000. Exploring Visions: Self-monitoring and Evaluation Processes within the Nepal-UK Community Forestry Project in Learning-based Approach to Institutional Assessment. Learning from Change: Issues and Experiences in Participatory Monitoring and Evaluation. London, UK: IDRC Intermediate Technology Publications Ltd. [pp 15-31]

IDS 1998. Policy Briefing. Participatory Monitoring \& Evaluation: Learning from Change, 12.

LEE, K.N. 1993. Compass and Gyroscope: Integrating Science and Politics for the Environment. Washington, DC: Island Press.

Malla, Y., Barnes, R., Paudel, K., Lawrence, A., Ojha, H. \& Green, K. 2002. Common Property Forest Management in Nepal: Developing Monitoring Systems for Use at the Local Level. Final Report on NRSP/DFID 7514.

McDougall, C., Ojha, H., Banjade, M., Pandit, B.H., Bhattarai, T., Maharjan, M. \& Rana, S. 2008. Forests of Learning: Experiences from Research on an Adaptive Collaborative Approach to Community Forestry in Nepal. Kathmandu and Bogor: CIFOR, ForestAction and New Era.

Ojha, H.R. 2008. Reframing Governance: Understanding Deliberative Politics in Nepal's Terai Forestry. New Delhi: Adroit Publishers.

Ojha, H.R., Pokhrel, B., McDougall, C. \& Paudel, K. 2003. Learning to Govern: How to Improve Monitoring System in Community Forestry. Journal of Forest and Livelihood, 2(2): 23-34.

Senge, P.M., Kleiner, A., Roberts, C., Ross, R.B., \& Smith, B.J. 1994. The Fifth Discipline Fieldbook. New York: Doubleday.

\footnotetext{
1 Different stages of the moon reflect different levels of progress in comparison to the expected output. No moon means no progress, new moon presents some progress and the need to do more, three quarter moon means remarkable progress but still some more to do and full moon means progress as expected.
} 